Torp O., Knudsen J. B., and Rønneberg I. (2018). "Factors Affecting Implementation of Lean Construcxtion" In: Proc. $26^{\text {th }}$ Annual Conference of the International. Group for Lean Construction (IGLC), González, V.A. (ed.), Chennai, India, pp. 1261-1271. DOI: doi.org/10.24928/2018/0234.Available at: www.iglc.net

\title{
FACTORS AFFECTING IMPLEMENTATION OF LEAN CONSTRUCTION
}

\author{
Torp, Olav ${ }^{1}$, Knudsen, Jens Biermann ${ }^{2}$, and Rønneberg, Ingeborg ${ }^{3}$
}

\begin{abstract}
Research has shown advantages an organization can obtain by implementing lean methodology. However, when implementing new philosophies like Lean Construction, there are always some challenges to overcome. Examples could be lack of basic knowledge about the theory/philosophy behind lean, lack of willingness to change, implementation process in an organization, lack of clear objectives/visions with the implementation and top management involvement.

The authors of this paper have worked with implementation of lean principles in a Norwegian contractor company. The contractor is split into several sister-companies, acquired over the past 40 years. Some of the sister-companies have succeeded in implementing lean, while others have not succeeded well. The authors will evaluate how the organization have planned to implement lean in an efficient and sustainable way, and what factors that have affected the implementation. The research methodology used is case study, where the different sister-companies are the cases. Research from the case study of lean implementation will give a better understanding for similar cases. It will also address how to overcome challenges related to the implementation process in similar cases.
\end{abstract}

\section{KEYWORDS}

Lean construction, Implementation, factors of success, organizational transformation

\section{INTRODUCTION}

Lean Construction have recent years received more and more attention. Large Norwegian project owners and contractors have started implementing lean principles and tools. Among the most common applied principles, you can find Last Planner System (LPS) (Ballard, 2000). Principles like Integrated Project Delivery (IPD), Target Value Delivery

\footnotetext{
Associate Professor, Norwegian University of Science and Technology, Trondheim, Norway, +47934226 73, olav.torp@ntnu.no

2 Assistant Construction Manager, Backe Entreprenør Holding AS, Oslo, Norway, +47 47606 270, jens.biermanknudsen@backe.no

3 Assistant Construction Manager, Backe Entreprenør Holding AS, Oslo, Norway, +47 93497227 , ingeborg.ronneberg@backe.no
} 
(TVD), takt-time planning, Set Based Design (SBD), and Choosing by Advantages (CBA) are also getting increased attention in the industry.

There will always be challenges to overcome when implementing lean principles and tools. Bygballe et al. (2014), Chesworth (2015), Neto et al. (2007), Howell et al. (1998), Höök et al. (2008) and Arbulu et al. (2006) have addressed different challenges. Some example of challenges are lack of conceptual understanding of the philosophy and theory, urgency to change among individuals (Mann 2014), implementation approach, and lack of lean culture.

The purpose of this research is to identify factors affecting the implementation of lean in a construction contractor holding company, and its underlying sister companies. This will help us understand implementation in different cases. We aim todescribe challenges with implementation and how they were met in specific situations in the sister companies. The research questions to be answered are; What challenges occur when implementing lean? How could these challenges be met when implementing lean in a fragmented construction company? This research will be based on Lean Construction literature, and use a case study to answer the research questions.

\section{TRANSFORMATION PROCESSES AND LEAN CONSTRUCTION}

Kotter (2007) points out eight critical factors every organization have to deal with to handle a transformation process. The first four steps are establish sense of urgency, forming a powerful guiding coalition, creating a vision and communicating the vision. The first four steps are meant to dissolve status quo in the organization. Then the implementation and use the new methodology, tools and/or philosophy should start. The next four steps are then empowering others to act on the vision, planning for and creating short-term wins, consolidating improvements and producing still more change and finally institutionalizing new approaches.

An implementation process may take several years before the future state becomes the new status quo. Organizations need to keep up the hard transformation work, in order not to lose the momentum (Kotter 2007). During such a phase of transformation, it could be preferable to hire or relocate dedicated individuals with experience in order to enhance the progression. The new standard achieved after earlier steps should now be in place. However, even though the conceptualities of the future state are now well established in the organization, the top-management needs to constantly focus on the future state going forward.

The interest for lean methodology in construction have evolved trough two different interpretations (Koskela et al. 2002). One interpretation relates the use of lean production methods in construction, and the other is what today is addressed as Lean Construction ("LC"). LC have used lean production theory as basis to evolve in order to become an independent theory-based methodology. There are still some common factors practitioners focus on, which are to eliminate waste, maximize costumer value and pursue continuous improvements. (Koskela, 1992; Womack \& Jones, 2003). Even though the road to achieve these factors varies. 
Since the introduction of LC, the approach of research has been focusing on difficulties and challenges with implementation of a lean practice in construction companies.

Many organizations have tried adopting lean into their daily operations, but not all have accomplished to sustain it. In Knudsen (2016), a LC-expert was asked about challenges, and her response was that the killers were lack of leadership together with no strategic plan or vision. Further, she comments that organizations need to start out small and test their ideas within a specific project. A good ambassador is preferable, in order to get other employees on-board. When momentum is created and you start deploying ideas and initiatives, results will come along. However, it requires commitment from everyone involved. When you have satisfying results, it is crucial to communicate these out to other parties in the organization.

Arbulu et al. (2006) proposed a lean transformation approach in construction, which maintains current state operations while the transformation process rolls out on designated projects. This gives the organization time to adjust its leaders and project teams, and prepare them for the transformation. The organization will also have good control on when and where the break point between current state and future state will occur. This, along with top-down leadership support is a preferable approach.

Moreover, research has also shown that in order to achieve a successful implementation these five key elements need to be in place; (1) Vision, (2) Skill, (3) Incentive, (4) Resources and (5) Action Plan. If all elements are in place, a change will be possible. Lack of one or more will probably result in an unsatisfying result (Larson 2003).

Höök et al. (2008) points out it is not enough just implementing and start using lean tools and principles without striving after a common lean culture among the employees. A lean culture is not achieved overnight; it takes a lot of practise and doing, before it is a natural extent of any employee. A proven way to engage employees to become more involved and empowered could be done, according to Diekmann et al. (2004), with a tool that gives employees daily feedback on their actual improvement. To move towards a lean culture, it is important to have proper arena to talk about improvement. A combination of involving parties, talk about problems, root causes and further find solutions as a team will persuade others to join the effort (Tillmann et al. 2014). If the top-management pursue and focus on sharing knowledge and experience throughout the organization, the organization itself will be even more capable to handle and challenge the status quo. Hence, the company should strive to create an organizational culture where the focus is to seek continuous improvements (Chesworth, 2015).

"Without a Lean management system in place to support the new physical or procedural arrangements, people are left to rely on their old tricks for fooling the system, using familiar workarounds to get themselves out of trouble", Mann (2014).

\section{METHODOLOGY}

The purpose of this paper is to identify factors affecting the implementation of lean construction and how to succeed with implementation of lean in a fragmented contractor company. The research questions to be answered are what challenges occur when 
implementing Lean Construction, and how we can overcome the challenges when implementing Lean in a fragmented construction company. Yin (2013) states that choice of research method in a large part depends on your research questions. The more your questions seek to explain some present circumstance (e.g. how and why some social phenomenon works) the more that case study will be relevant. Hence, a case study described by Yin (2013) could fit with this kind of research questions. Two master students contributed to the research through their work with their master thesis (Knutsen 2016 and Rønneberg 2017), and their research results are merged into this paper.

The contractor company consists of a holding company with 12 widely geographically spread subsidiaries (each a "division", collectively "divisions"). The divisions are acquired over a period of 40 years. The divisions are responsible for their day-to-day operations.

To answer the research questions, the first one is firstly addressed through a literature review, thereafter by a case study. The case study includes interviews and a questionnaire to identify factors affecting the implementation in the specific situations. The last question on how to overcome the challenges with implementing lean in a fragmented company is addressed through the same case study.

The case organization is currently in the middle of an implementation process with lean and lean is already well anchored in the company's strategy. The top-management want a lean approach to their daily operations in their organization, because they believe it will help them realise their goal on every end product, which is zero personell injuries, zero need for rework and seven percent profit margin (the 007-goal).

The case study is based on a prior literature review, as well as interviews, observations, a questionnaire, document studies and informal conversations with people involved in the process, both internally and externally. To get knowledge about the implementation process in the holding company, the first step was in-depth interviews with 3 key stakeholders in the holding company and with the external consultant, an expert on lean implementation involved in the implementation process. To get knowledge about the situation in the sister-companies, a questionnaire together with in-depth interviews with key personnel in the company was performed. The questionnaire was sent to seven sister companies that already had started implementing lean. 151 persons were asked to answer the questionnaire, where 123 answered the questionnaire. The questionnaire included questions regarding the employees' knowledge about the implementation process, its goals, information about the implementation from the management, how satisfied the workers were with the implementation and the effects of the implementation. The interviews were performed with 4 of the companies. In the interviews, the top management of the sister companies were asked questions regarding the implementation process; Why the organization wanted it, how to ensure a sustainable future state and other questions relating to implementation process were asked. Informal conversations with key-personnel involved in the process supported the findings from the interviews. 


\section{FACTORS AFFECTING THE IMPLEMENTATION OF LEAN CONSTRUCTION}

The results summed up in this section are based on the literature review, the interviews and the questionnaire.

\section{HOLDING COMPANY FINDINGS}

The final decision to start implementing lean construction in the organization was by no means an impulsive decision. After some careful consideration and consulting, the organization's top-management believes that daily operations based on lean philosophy is highly preferable. Increased demands from both private and public owners have led them towards taking benefit of the advantageous that comes with lean philosophy. The transformation is not highly needed, but rather a strategic move to position themselves for the future. This helped create some kind of urgency, which is preferred to get the transformation process going. Further key-personnel have taken on necessary training to handle uncertainties that may arise, like questions from concerned individuals. This will, and has in the case helped calm down strong individuals, which have resisted the change process from the beginning.

The aim of the organization is that within 2 years, lean construction should be the way they do things. Due to absence of any desperate need to change, the organization has the possibility to progress in a healthier manner.

The organizaiton faced lack of internal competence on lean construction. Therefore, a consultant company was hired. The consultant company developed a roadmap for the implementation process. The purpose of the first steps, outlined in Kotter (2007), is to dissolve status quo in the organization. Going forward, the roadmap is like a guiding tool to finally transform the organization into a self-driven one, which always searches for continuous improvements. During the work with the case, several commonalities with Kotter's eight steps occurred.

\section{SISTER COMPANY FINDINGS}

After the anchoring within the organization leaders, the process takes a step down. When continuing the transformation process into this division-level of operations, it is highly important to get manager's and key-personnel's attention. They are not supposed to create a new vision, which already is enacted. Rather show commitment and ownership to the transformation taking place. The consulting firm maps out, in consolidation with internal users, on which process they should start their improvement work. To help them locate urgent problem areas they use a process-mapping tool. When an improvement project is chosen, an A3 is drafted and further executed. Getting proper training and conceptual understanding among employees is important to keep the process going, and certainly when the consultants start backing off after 4-6 months.

One finding, which most likely reflects the managers vision of status quo and/or their point of view of lean as a production theory, is that some of the divisions showed much greater interest in starting the implementation process, others have been waiting for results from one of the early adopters. The questionnaire shows that the two companies 
with most successful implementation processes thus far both have had a feeling of urgency for change. According to Mann (2014), a feeling of urgency to change is onestep to a successful organizational change. In these two companies, we also observe that they have an internal driving force behind the implementation process, which also is according to Mann (2014).

Another important challenge that occurred was to communicate a proper vision throughout the whole organization from the holding company down to the sister companies. The feedbacks from divisional managers were positive. Hence, it has shown that even though managers responded positively to the implementation, not all of them understood the extent of the process. Further, the road to success demands a lot of involvement and commitment.

Before the process rolled out to the divisions, an indicative progression was mapped. The estimated time each of the divisions were supposed to get help from the consultants, was estimated to about four months. Reality has shown that all of the five divisions that have been through the process with support from the consultant company, have exceeded the estimated timeframe. For the sister-companies, the cooperation with the consultant as an external facilitator have been very important. This also is in line with Womack and Jones (1996) and Ballard and Kim (2007).From the questionnaire, $51 \%$ of the employees are very satisfied or satisfied with the cooperation with the consultant, while $4 \%$ is dissatisfied with the cooperation.

One factor for successful implementation of changes is according to Arbulu and Zabelle (2006) resources. Lack of resources to support the implementation will lead to frustration in the organization. The holding company has supported the implementation both economically and by resources, through the external consultant company. From the questionnaire we can observe that two of the sister companies would like more support from the holding company. One of these companies still state that they have had successful implementation, the other have had challenges with the implementation.

\section{PROJECT LEVEL FINDINGS}

After a couple of A3 improvement projects have been going on at respective divisionoffices, the improvement work carries out on construction projects. The purpose is to get proper anchoring within the division-management and further withstand the improvement work at project-level. When the improvement work starts out on construction projects, it is important not to "forget" to keep working with the improvement within divisionmanagement; this is carefully monitored by the consultants. Typical improvement projects out on construction projects where planning, and involvement of parties to reach a common goal. At this level, the Last Planner System is implemented.

From the questionnaire, $90 \%$ of the employees agree or partly agree that they know why Lean Construction is implemented in the organization. Around $15 \%$ of the employees partly or fully agree that they did not have enough information about Lean Construction prior to start of the implementation process, where there are sistercompanies where up to $12 \%$ of the employees fully agree that they did not have enough information about Lean Construction. When asking about whether the employees had enough information about the implementation process, around $20 \%$ disagree that they 
had enough information about the implementation process. There are variations between the sister companies, where in one company all agree that they had enough information about the implementation process, while in one of the companies $32 \%$ disagrees that they had enough information.

From the questionnaire, $51 \%$ of the employees agree or partly agree that the implementation of Lean Construction have been successful for their respective company. In this respect, there are large variations between the companies, from $84 \%$ in one company to $20 \%$ in another company. The questionnaire shows that the company where projects became more productive after implementing Lean are the same companies that most often use Lean Construction elements in their organization and projects.

\section{DISCUSSION}

A big responsibility to succeed lies with the top-management, especially when the consultants starts backing off. From that point, the top management and the division management and other key-personnel are going to be the superior, and all questions and reporting are going to end up in their lap. The work with the in-depth interviews revealed that the top-management had not gone through the implementation process before the first division had. This caused some ripple effects at the early adapters, because they did not have proper backing from top-management. Another finding was the absence of common forum for managers to talk about lean across the divisions and to exchange learnings and experiences.

The implementation process has to be seen as a simultaneously top-down, bottom-up implementation approach. This because the transformation seeps downwards from the top-management into the organization, throughout each division and further to projects within the divisions. What is seemed to be beneficial from this approach is that even if the transformation process doesn't carry out as planned, the transformation will keep going. This because the process will have all necessary backing from higher up the organization.

A problem met is actually caused by the top-down implementation. Individuals affected by the transformation have felt that they are the root cause, not the topmanagement. Even though that is not the case. In spite of this, a lesson is that the holding company itself should have done more of the improvement work internally before any of the divisions.

The holding company aim to change the culture in the company. Changing an organizational culture is not done overnight. This is supported in both the literature and case findings. It will probably take years of practice before the chance of major setbacks is gone. Strive for a solid lean culture among the employees requires first dedication from every party involved. Further, you need a good conceptual and theoretical platform to work from, and key personnel with executive power as ambassadors. The consultant company was aware of this challenge, so they were not only focusing on implement just leantools and practises. They also tried to involve and engage employees to strive for improvement at all levels. A challenge the consultants have met is that the employees 
does not raise any questions, and that is definitely not because everything is very clear, rather a cultural challenge.

One of the consultants believes that the challenge is not only to implement new things to an organization, but to get rid of old habits. A consistent finding was that employees, which came straight out of school, had less problem adopting a lean mind-set. This is most likely because they possess no earlier experience related to the current state of daily operations.

Due to the highly fragmented organizational structure, several strategic challenges were raised. One central challenge is that the holding company does not have any direct executive power over all the divisions. In other words, the holding company cannot force a division to start the process, but the twist is that key personnel have seats within every company board. So a challenge has been an absent consequence culture between the holding company and the division. Even though, this challenge has been coped with to a certain extent with success stories from other cases, and a general belief that the change will contribute to the strategic 007-goal of the organization.

During the implementation process, the divisions get supervision twice a week. This will prevent the consultant's resources from being stretched thin, since there are constantly two divisions involved. A typical challenge with a third-party transformation is the fact that the third party actually does not have any direct executive power over employees within an organization. In other words, a consultant cannot in the given case tell and decide what the employees should do. Therefore, their approach is more directed into encouraging people to do it. This should be safeguarded by satisfying educational training, as well as adequate anchoring within top-management. It is a false impression when the consultants do not see any kind of improvements from week to week, and the consultants carry out all the improvement work. In some cases, it has been the reality. A triggering factor has been lack of commitment from key personnel, like the manager for a division. It is his or her responsibility to encourage his employees to seek continuous improvement, and actually check if they are succeeding. Especially after the consultant's work is done, if there is no following up or any kind of reporting system throughout the organization. In addition, especially within every division, the relapse to old habits is closing in.

Further responsibilities are to designate a champion. A champion is a person, which first is dedicated and truly believes in the future state. Further, he takes over the consultant's role, which includes the following up of all the improvement-projects. A good system for reporting needs to be initiated, and the top of the reporting chain have to care. The preferred system for reporting is by A3, this makes it clear for every party where they stand, what is needed, and at last what they have accomplished.

\section{CONCLUSION AND RECOMMENDATIONS}

In this paper, the authors have addressed how a general contractor implements lean throughout their organization, from a holding company, through its sister companies and down to the project level, and what factors affect the implementation. One main finding is that the implementation should follow the line from top organizational management, 
down to its divisions and further into construction projects. Although early adopters could give positive impact on others, the implementation process should follow this line. We have revealed how the consultants work with the organization to achieve their goals, and the similarities to Kotter (2007). The final goal is to have an organization that continually strive for continuous improvements.

Further, the authors found the implementation plan/strategy, developed in collaboration between the consultants and the holding company to be satisfying. Yet, there are still challenges rising, which need to be handled correctly. For instance, the fact that the transformation period has exceeded in most divisions. This might be caused by the absence of a burning platform or lack of ownership among key personnel. Even though, the study confirms that top management support and anchoring is an important factor for successfully implement and sustain the new behaviours.

Moreover, findings in the case are backed up by the literature, with exception of a consultant driven lean implementation process. Even though a consultant driven process seems to be the right choice for the organization, due to lack of internal lean resources. An outcome has been challenges concerning the handover from the consultancy to the organization, after their process is finished. Therefore, designated champions will get the consultants responsibility of following-up on ongoing and future improvement projects.

Lastly, we found out there was not any forum for discussion of lean across the divisions. Moreover, no common arena for exchanging valuable experience and learnings from their improvement work. After all, despite the fact that the road to fulfil the vision is long, the organization seems determined to do so. Therefore, to establish learning forum across the organization is highly recommended.

Through literature search, interviews with the holding company, the questionnaire and interviews with five of the sister companies, important factors for successful implementation were identified. For successful implementation of Lean Construction in a holding company with its sister companies, the following factors are important;

- implementation starts with the holding company with top management support through the sister company and its management and down to the projects

- information and communication around the implementation and the lean principles, from the holding company, through the sister companies down to the project level is important

- showing success from early adopters in the implementation is important

- if use of external facilitator, support with resources both from the holding company and the sister company is necessary, building internal competence to use when the consultant company is no longer there.

- marking of victories and recognition of successes along the way, both at holding company level, sister company level and at the project level is important

- establishing a forum for exchange of experiences between the holding company, the sister companies and the projects will give good support on all levels 
Some of the divisions have, prior to the consultant driven process, taken sporadic use of lean tools and principles. Further, it would be interesting to compare the lean-ness in such division with a division where consultant driven implementation is the case.

Moreover, it was found that one of the most successful divisions, in term of revenue, have not officially gone through an implementation process. Therefore, it would be interesting to do research what their best practice is, and compare their behaviour to lean principles.

\section{REFERENCES}

Arbulu, R., and Zabelle, T. (2006). "Implementing Lean in construction: How to succeed." Proceedings International Group for Lean Construction (IGLC)-14,Santiago, Chile.

Ballard, H. G. (2000), The last planner of production control, PhD thesis, Faculty of engineering, The University of Birmingham.

Bygballe, L. E., and Swärd, A. (2014). "Implementing lean construction: A practice perspective." 3-14, 22nd Annual Conference of the International Group for Lean Construction, Oslo, Norway.

Chesworth, B. (2015). "Misconceptions of Lean: Why Implementation Fails." 621-630. $23^{\text {rd }}$ Annual Conference of the International Group for Lean Construction. Perth, Australia.

De Paula Barros Neto, J., and Da C. L. Alves, T. (2007). "Strategic issues in lean construction implementation." 15th Annual Conference of the International Group for Lean Construction, East Lansing, Michigan, USA.

Diekmann, J. E., Krewedl, M., Balonick, J., Stewart, T., and Won, S. (2004). Application Of Lean Manufacturing Principles To Construction. Construction Industry Institute.

Howell, G. and Ballard, G. (1998). Implementing lean construction understanding and action. $6^{\text {th }}$ Annual Conference of the International Group for Lean Construction. Guaruja, Brazil.

Höök, M., and Stehn, L. (2008). "Lean principles in industrialized housing production: the need for a cultural change." Lean Construction Journal, 2, 20-33.

Knudsen, J. B. (2016). "Challenges with implementation of Lean Construction in BackeGruppen." (In Norwegian). Norwegian University of Science and Technology.

Koskela, L. (1992). Application of the new production philosophy to construction. Stanford university Stanford, CA.

Koskela, L., Howell, G., Ballard, G., and Tommelein, I. (2002). "The foundations of lean construction." Design and construction: Building in value, 211-226.

Kotter, J. P. (2007). "Leading Change: Why Transformation Efforts Fail." Harvard Business Review, Harvard Business Press.

Larson, A. (2003). Demystifying Six Sigma: A Company-Wide Approach to Continuous Improvement. AMACOM, New York.

Leong, M. S., Ward, S., and Koskela, L. (2015). "Towards an Operational Definition of Lean Construction Onsite." $23^{\text {rd }}$ Annual Conference of the International Group for Lean Construction. Perth, Australia. pp 507-516. 
Mann, D. (2014). Creating a Lean Culture: Tools to Sustain Lean Conversions, Third Edition. CRC Press.

Rønneberg, I. (2017). Factors affecting the implementation of Lean Construction (In Norwegian). Norwegian University of Science and Technology.

Stevens, M. (2014). "Increasing Adoption of Lean Construction by Contractors". $22^{\text {nd }}$ Annual Conference of the International Group for Lean Construction. Oslo, Norway, pp 377-388.

Tillmann, P., Ballard, G., and Tommelein, I. (2014). "A mentoring approach to implement lean construction." 22nd Annual Conference of the International Group for Lean Construction. Oslo, Norway.

Womack, J. P., and Jones, D. T. (2003). Lean Thinking: Banish Waste and Create Wealth in Your Corporation, Revised and Updated. Productivity Press, New York.

Yin, R. K. (2013). Case Study Research: Design and Methods. SAGE Publications, Inc, Los Angeles. 